\title{
Where Have All Our Leaders Gone?
}

\author{
Marvin L. Birnbaum, MD, PhD
}

In his remarkable book, “A Force for Change," John Kotter clearly separates leadership from management. Early in the development of his thesis, he describes both leadership and management from four aspects: 1) Creation of an agenda; 2) Development of a human network for achieving an agenda; 3) Execution; and 4) Outcomes. Leaders seek to establish an agenda, while managers plan and budget. Establishing an agenda consists of "developing a vision of the future, often the distant future, and strategies for producing the changes needed to achieve that vision." While managers attempt to organize and staff by establishing some structure as a means for achieving an agenda, leaders create teams that understand the vision and accept and promote strategies to attain their goals. Managers attempt to execute by taking control and by using the skills of problem-solving. Leaders do not need to control, but instead "energize people to overcome major political, bureaucratic, and resource barriers to change." Managers affect outcomes through rendering issues to predictable solutions through the creation and maintenance of order; leaders produce new approaches and new products.

Given these premises, why is medicine in trouble? Where are our leaders? Judge for yourself. There have been some remarkable leaders: Peter Safar, Ron Stewart, Rudolph Fry, Corrado Manni, Bill Gunn, Leonard Cobb, R.A. Cowley, and many more. They all had visions and were able to achieve them. But, where have all the leaders gone? Where is the vision? Without clear vision to the future that is open, understood, and actively supported, we will succumb to management. As long as we attempt to mimic the managers who seek to wrest control from us for financial gain, we will not survive as an independent craft in control of our own destiny. Managed care is here, whether it be in the form of payers or government.

I do not know how or when medicine became so passiveaggressive. We may be aggressive in the processes of patient care, yet we have approached the structure of our profession with great passivity: we wait to see how it will go, what will happen to us next. We have remained on the sidelines. Management has assumed a stronger and stronger role: they, and not we, have moved our profession into an evolving structure that supposedly fits our times and our pocketbooks. We are lambs. We bleat, but passively head in the direction dictated by the managers of the flock. We passively are allowing ourselves and our profession to be managed. We leave the structure of our profession to others.

Perhaps it is because our training did not include the skills so necessary to sustain the independence of our craft. Perhaps, we have been too busy to think about such things. Perhaps, we have not concentrated on developing leadership skills and have not produced capable leaders.

The question is what can we do to optimize our positions? What can we do to return to the role of patient advocate? After all, patient advocacy is our principal role as physicians, nurses, and paramedics. In the changing system, who is the patient's advocate?

Prehospital medicine is in a unique position in this whole milieu. No matter where we practice, there exists the potential to broaden the scope of what and how we practice to include better and more cost-effective means of providing care. We have a narrow window of opportunity through which to thrust ourselves into the public-health arena and join hands with the operative side of public health. We must involve ourselves in those aspects of public health that are a natural progression for us and will contribute much to the communities for which we are entrusted with the emergency health care. We must move out of the managed emergency-department environment into the community. We must provide much of the care now rendered in the emergency, accident, and injury areas in the outof-hospital setting. We can do it better and at less expense than we can in the emergency departments or clinics; we can set the example for the other disciplines, and lead the way into the 21 st century. But to do so will require leadership. Move past the managers and out into the community. Don't just talk about out-of-hospital care as a mission. Do it. Take control. The only other option is to remain within the sanctity of the emergency departments and lose what little independence we have left.

Look around you. Evaluate your peers and identify those who possess the characteristics of leaders. We need leaders with vision; we do not need managers. Our leaders must have a vision of where we must go. They must be able to set a clear path to widen our scope of practice that concentrates on prevention, public health, and primary care. They must have the ability to lead us there. And, we must actively support this vision. We must participate. Without vision, managed care will swallow all in which we believe, all in the name of better (i.e., less costly) care. For too long, we have continued to follow medical managers. They come into positions demanding leadership by means of ascension, not because of their leadership ability. They fill our departmental chairs and organizational offices. They are not trained in management and have little leadership ability. They attempt to assume the roles of leaders without the talents and skills required. Look around you, and choose carefully. We have much at stake. Cast away your passivity. Move your visions toward reality. It's up to you.

\section{Bibliography}

Kotter JP: A Forre for Change: How Leadership Differs from Managemenl. The Free Press, New York. 1990.
Starr P: Social Transformation of American Medicine. Basic. New York. 1982. 


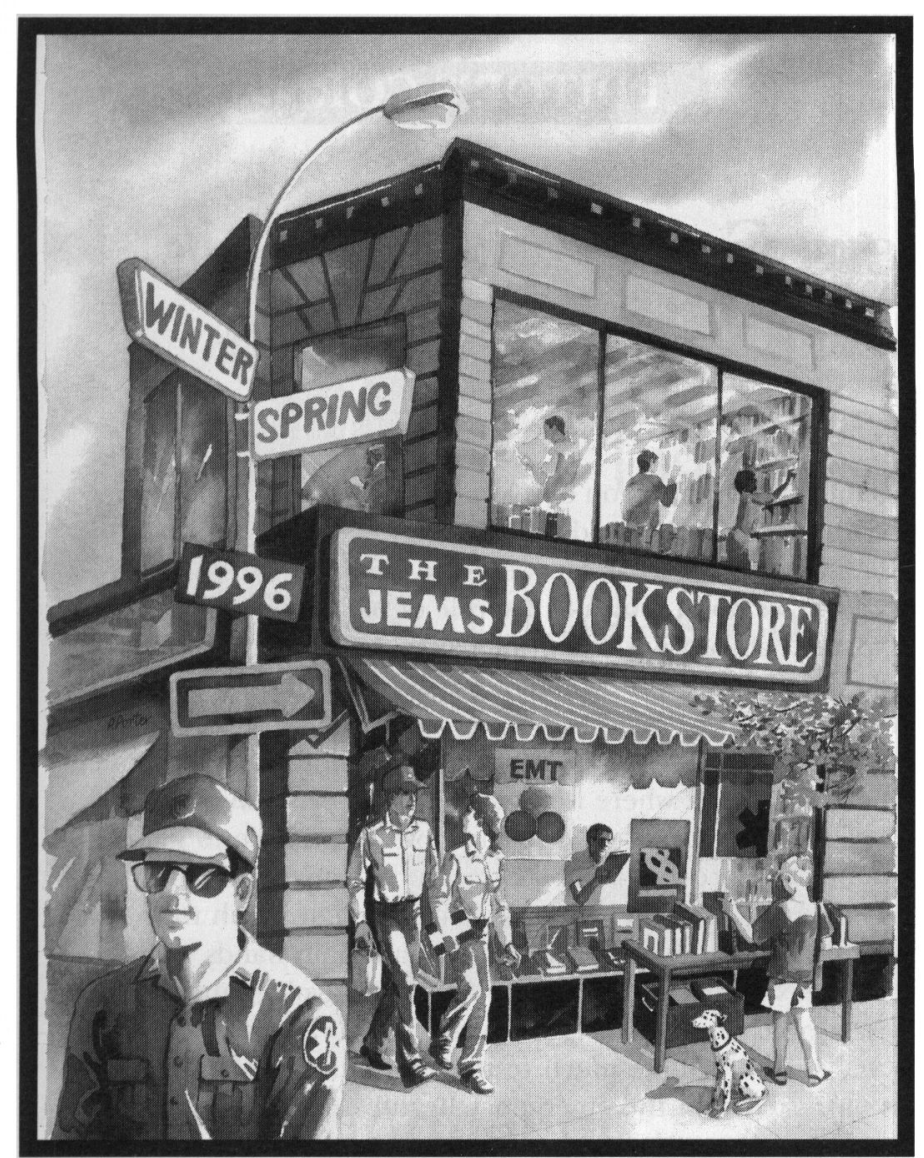

\section{EMS Management: Beyond the Street}

Joseph J. Fitch, PhD; Rick Keller, EMT-P;

Doug Raynor, PhD; and Chris Zalar, RN

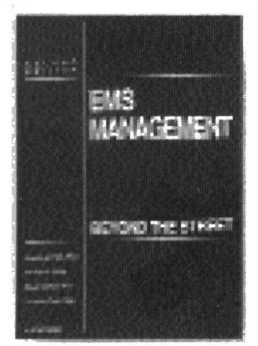

From abstract topics, like understanding the changing work force, to practical matters such as disciplinary action, this sequel covers all the areas successful EMS managers need to know.

The authors discuss everything from finance to operations-from kickbacks to handling the media-in a writing style that's easy to follow. Whether you're a longtime administrator or someone who's just now aspiring to move "beyond the street" into management ranks, you'll want to own this bigger and better second edition of an EMS management best seller. PB, 432 pages.

CJ24788

$\$ 42.95$

\section{Prehospital Systems and Medical Oversight}

National Association of EMS Physicians and National Resource Center; Alexander Kuehl, MD, Editor

A revision of the EMS Medical Directors' Handbook, this second edition includes: a broad overview of EMS; a historical perspective and mechanisms for the provision of medical oversight; operational issues; comprehensive glossary. Infectious diseases, quality management, and legal issues are only a few of the topics covered in this text's 48 chapters. Ideal for professionals involved in the medical aspects of designing, implementing, and operating EMS systems. 2nd edition. PB, 492 pages.

CJ06580

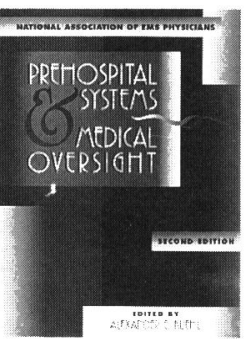

$\$ 44.00$

\section{Step into the Jems Bookstore... We're always open!}

Featured Selections

$\square$ NEW TITLES

$\checkmark$ MANAGEMENT

$\square$ EDUCATION

$\square$ REFERENCE

$\square$ CERTIFICATION

\section{Prehospital Care Administration: Issues, Readings, Cases}

Joseph J. Fitch, PhD

This work is a blend of original and previously published articles from key professional journals and trade magazines. The text serves as a ready reference for every EMS administrator. Topics covered range from handling human resource issues to reimbursement and EMS system design. More than 100 articles represent both landmark

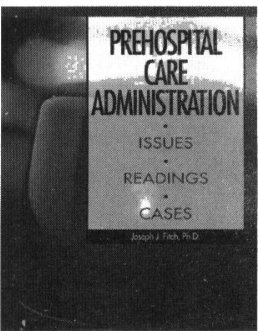
cases shaping the profession as well as original articles which offer new insights for the future. Prehospital Care Administration is edited by Joseph J. Fitch, founder of Fitch and Associates, Inc., the most widely utilized EMS medical transportation firm in North America. $\mathrm{PB}, 746$ pages

CJ25879

$\$ 42.95$

\section{Shiftwork Safety and Performance Manual}

Peggy Westfall, Glenn McBride

The subject of shiftwork has emerged as a most important subject of this decade. Shiftwork Safety and Performance Manual is designed for managers, supervisors and trainers of our 24-hour performers, those working people who commit to "time travel" around the 24-hour clock. Built in to this manual are extensive communication tools and references to help you train the most important people - your employees and your boss! 3-Ring binder format. $\$ 99.95$

\section{HOW TO ORDER}

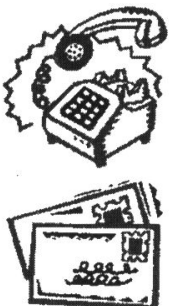
Phone (800) 240-0703

Mail (800) 535-9935

Mosby-Year Book/Jems Bookstore 11830 Westline Industrial Drive St. Louis, MO 63146 